\title{
From Extension to Engagement: Mapping the imaginary of
}

wearable technology

\author{
ANNE CRANNY-FRANCIS \\ Macquarie University, Sydney, Australia
}

\section{ABSTRACT}

This paper maps the metaphors that have been used to facilitate human engagement with wearable technologies - extension, enhancement, augmentation - and locates the values and assumptions about the body and technology that they articulate. At the same time it considers the figure of the cyborg, in which many of these metaphors are incorporated fictionally and theoretically, and locates in this figure not one (interrogative, critical) meaning, but many possible meanings. The paper then goes on to explore a recent reconfiguring of the human-technology relationship (Schroeder and Rebelo's (2007) analogy with the relationship between musician and intstrument), which it describes in terms of engagement - and to propose further that we need to embrace fully the embodied character of this relationship, in order to realize the most creative possibilities of our relationship with the material world as expressed in this recent technology.

\section{KEY WORDS}

• technology $\bullet$ wearable $\bullet$ body $\bullet$ hybrid $\bullet$ cyborg $\bullet$ difference $\bullet$ extension $\bullet$ prosthesis $\bullet$ enhancement $\bullet$ augmentation $\bullet$ engagement $\bullet$ frottage

\section{INTRODUCTION}

Since the 1980s critical writings about the relationship between humans and technology, including wearable technology, have used a number of major metaphors to conceptualize the nature of this interaction - extension, prosthetic, augmentation. These metaphors 
have enabled people to use the technology by giving them an imaginary relationship with it, which enables it to be naturalized into their lives; to seem unexceptional. A striking example from the early years of virtual reality and the internet is, of course, William Gibson's metaphor of the matrix or cyberspace in Neuromancer (1986). There is no literal matrix or cyberspace; indeed as some theorists have argued, the internet and the world wide web are temporal, rather than spatial, constructs (see Chesher, 1997). However, with that imaginary creation in mind users who had never been involved with any form of information technology moved almost seamlessly from the typewriter to the word processor, quickly learning to exploit the capabilities of this new technology.

Yet, even that movement was not without major cultural significance. The typewriter was a major technological application of the late $19^{\text {th }}$ and $20^{\text {th }}$ century, which had transformed work practices. It was also a feminized application': typing pools (i.e. rows of typists doing the equivalent of data entry from hand-written manuscripts) were almost entirely female. The only men who regularly used typewriters as part of their lives were writers and journalists, and then the machines were given compensatory masculinized characteristics; in fiction, they were always 'old and beat up' - verbal reassurance that they did not render their users effeminate.

The word processor/personal computer had a different provenance - geek boys, computer nerds - a stereotype that was thoroughly and unflatteringly masculine. And it is more correct to note that the move to this technology was enabled not only by an imaginative construct (the matrix, cyberspace) that enabled users to conceptualise the activity in which they were involved, but also by Apple's development of its graphic-user interface (GUI) that introduced an icon-based desktop to users. Replacing the DOS interface with its strings of apparently meaningless verbal symbols, Apple gave users metaphors such as desktop, folder, file, document, trash by which they could organize the material they 
generated. None of these are 'real' in any real-world sense; they are imaginary constructs that enable users to manipulate the technology in effective ways.

I am using the notion of 'the imaginary' as conceived by philosopher, Michelle Le Doeff and glossed by Elizabeth Grosz as 'a kind of "thinking-in-images", the use of narrative, pictorial or analogical structures within knowledges' (Grosz, 1989: xix). For Grosz this also marks the imaginary as 'symptomatic of an (intellectual and political) elision: it marks those places within philosophical texts where the discourse is unable to admit its founding assumptions and must cover them over' (Grosz, 1989: xix). My study takes up these two different aspects of the imaginary. Firstly, in Le Doeuff's terms it is seen as enabling - in that we use this 'thinking-in-images' to move beyond the categorised and the known ('knowledge') into new experiences and new capabilities, which may subsequently be added to our repertoire of knowledges. Secondly, this imaginary does reveal the assumptions at the basis of these new experiences and associated capabilities. That is, the forms it takes and the complex of ideas and affects mobilizing them tells us about the nature of that engagement with technology. And note here that this imaginary is manifest in many different modes, genres and media - in philosophical discourse, as Grosz notes, but also in the narratives that scientists construct about their work and in the arts and in popular media, where it is a way of thinking through the changing technological (and accompanying social, cultural, economic and political) context in which we live.

As the essay also maps, the figure that most often populates this technological imaginary is the hybrid figure of the cyborg - part-human, part-machine. Ever since Donna Haraway's critical intervention in the debates about technology with 'A Cyborg Manifesto' (1991), the figure of the cyborg, already a mainstay of fictional interrogations of the technological imaginary, became also a major trope in theoretical writing where it was used to explore the interrogative potential of new combinations of human-animal and human-machine. My concern here is to note that the meanings of the cyborg, too, are 
multiple - just as their fictional representations include the original (Arnold Scwarzenegger) robotic Terminator (1984), the liquid metal (Robert Patrick) Terminator of Terminator 2: Judgment Day (1990) and Neo and his companions in The Matrix (1999). The hybrid/cyborg figure may be an interrogation of western society and values, as Haraway argued, but it may be the reverse. This is a crucial point, because of the prevalence of this figure in the many metaphorical domains of the technological imaginary - and because, as Grosz notes, the imaginary is intellectually and politically motivated. Mapping the technological imaginary of wearable technology, then, means both and simultaneously mapping the metaphors that have been used to articulate this imaginary, and the different manifestations of the hybrid (cyborg) figure that accompany those metaphorical constructions.

\section{WEARABLES}

In the 1980s and 1990s the term, 'wearable technology' conjured up Virtual Reality (VR) applications; now towards the end of the first decade of the twenty-first century, VR seems a rather quaint formulation. Not that VR has gone away, of course, as gaming companies are very aware, but its everyday applications no longer seem so attractive. There may be a range of reasons for that, including people's sickened responses to television broadcasts of VR-type simulations tracking US bombs to Iraqi targets; inevitably followed by apologetic references to the collateral damage (i.e. civilian deaths and injuries) caused by these attacks. Or earlier, Ronald Reagan's reported satisfaction that children playing computer games were learning to be the next generation's fighter pilots; 'training kids to kill', as critics termed it. Now people might use Wii to play various games, but there is much less publicity than in the 1990s about how the technology mirrors military applications.

In the first decade of the $21^{\text {st }}$ century wearable technology refers mostly to applications developed using new, 'smart' materials - nanotube fibres, electronic fibres that are strong, 
durable and weavable - that are used in textiles. These textiles can be used for a range of purposes, from wound dressings to sports clothing to military uniforms (Valigra, 2002; Adams 2005; Jewell, 2006). As well, designers and artists are using these materials in a range of artifacts - clothing and jewellery - that explore the nature of contemporary embodiment (Baurley, 2006; Charlesworth, 2007; CuteCircuit, on-line; Heiss, 2007; Kettley, 2007a, 2007b; Wallace, Dearden and Fisher, 2007). That is, designers use these new materials in clothing and jewellery in order to explore the ways in which users incorporate these artifacts into their lives - as identity, communication, comfort, play - and what this reveals of their understandings of the nature of embodiment.

This article explores the changing nature of this technological imaginary as it has informed the interaction with wearable technology since the 1980s. Of course, we can develop genealogies of wearable technology (e.g. Rhodes, on-line) that include earlier instances of wearables; however, this paper focuses on the period from the 1980 s and the transformation of everyday life and work through the pervasive use of personal computing. The analysis begins with one of the earliest metaphors used to characterize this relationship - extension, then considers a number of other facilitating metaphors and associated imaginaries, before dealing with some of the most recent writing on this topic, which stresses the fully sensorially, even erotic, embodied engagement with new, and specifically in many cases, wearable technology.

\section{EXTENSION}

There has always been an erotics of wearable technology, of course, even back in the days when wearables mostly meant geeky head-mounted gear that was used to create VR for its wearer. Its erotics was a straight-out erotics of power. The wearer was participating in the development of a technology that was seen as world-changing - always a buzz and which offered the individual wearer a freedom from mundane physical reality never 
before thought possible. Writings of the period have an onanistic quality as wearers exulted in the release offered by a range of visual stimuli, invisible to the outsider.

And this was a very specifically-gendered world. It was a boys' world, in which the devices were a kind of power-suit, a male dress-up that offered the gratification of power not only channelled through, but identified as, technology.

In this period the concept used to describe the human-technology relationship was extension - an interestingly phallic choice, given its provenance. Its obvious referent is basic tool use, using a stick or implement to extend the reach of human ability, as in Stanley Kubrick's famous scene in 2001: A Space Odyssey when the early primate picks up a bone and recognizes it as a tool (which he soon after uses to kill a rival!). In the VR experiments of the 1980s the human subject wore the computer/VR device in order to utilize the capabilities it offered, whether as a VR interface or other IT application in order to extend the capacities of human perception. At this early stage the technology was wearable, but not comfortable. It did not fit within the parameters of what we normally consider wearable, e.g. clothing, jewellery. It did not even have the comfort of a prosthetic device such as eye-glasses, which are sometimes included within a genealogy of wearable technology.

The reasons for this were technical; computing still at this point meant hard-shell technology. We might argue that there wasn't a sufficiently innovative 'imaginary' at work to enable it to become anything else; to conceptualise technology as anything but plastic shells or rubber sheaths containing silicon components and electrical writing. So wearable technology meant plastic components somehow attached to human users.

Interestingly, as noted above, the VR focus of much of this early wearable technology focused on individual perception; on introducing the user/wearer into a virtual world where 
$\mathrm{s} /$ he was freed from the gravity and dimension constraints of everyday life. This is the world of the mind-in-a-vat that sees the materiality of the world as a hindrance to the freedom of the mind (Latour, 2003). It is also the world of Neuromancer(1986) whose main character, Case despises his own embodiment so that when he is excluded from cyberspace: 'For Case, who'd lived for the bodiless exultation of cyberspace, it was the Fall. In the bars he'd frequented as a cowboy hotshot, the elite stance involved a certain relaxed contempt for the flesh. The body was meat. Case fell into the prison of his own flesh.' (Gibson, 1986:12). Case's engagement with cyberspace is such that he has to take special care not to neglect his physical body to the point that he dies of starvation.

\section{PROSTHETIC I: ENHANCEMENT}

The character of Case differs significantly from the helmet- and glove-wearing ITC pioneers in that he interfaces with technology via an implanted physical jack; Case plugs himself into the technology or, more correctly, plugs the technology into himself. This metaphor stays within the parameters of hard-shell technology, of course; simply making the internet a prosthetic extension of human being - or vice-versa.

An analogous fictional representation is the image of Captain Jean-Luc Picard of Star Trek: The Next Generation after he has been transformed into Locutus of Borg, a cyborg member of a collective entity called The Borg (1990). As the cyborg Locutus, Picard has been implanted with a weapon-arm (replacing his organic arm, or part thereof) and one of his eyes has been replaced with a complex visual sensor. We see Picard laid out on an operating table, multiply-pierced by drilling tools, his skin blanched to bone-white. We also learn that he is now psychically linked to the Borg entity. This image carries a weight of cultural associations and meanings, including the dread of being fundamentally changed, indeed invaded, by technology. This was a particular concern in the late 1980 s and early 1990s during the invasion of western society by a series of viral vectors, biological and technological; including AIDS, (fears of) Ebola, IT viruses transmitted by email (Cranny- 
Francis, 1995: 95-97). At the same time, however, this image of technological transformation and related powers is compelling, particularly as Picard's 'humanity' reestablishes control over his cyborged-being; he then has the power of the technology under the control of his rational human mind. As argued elsewhere (Cranny-Francis, 2000), the Picard-Locutus cyborg does not challenge conservative notions of being or the political assumptions of western male rationality; he incorporates and transfigures them. Again, the erotics of this figure is of power; to act beyond the reach of human corporeality, physically and psychically.

So in this case the cyborg is not the fundamentally interrogative figure it is sometimes considered to be, but a conservative construct that reinforces contemporary associations of power with middle-class, white masculinity. And as I have argued, it partly does this through a further association of the cyborg figure with the image of the crucified Christ, which has major cultural significance in the West (Cranny-Francis, 2000, 2006); that is, has a major role in the Western cultural imaginary.

\section{Cultural Imaginary: Christ as hybrid}

As Sarah Beckwith (1993) and others (Bynum (1991, 1995), and particularly Steinberg (1996)) argue, the body of Christ is a highly eroticized figure in the west. Its cultural and religious power is based not only on its sacred meanings (as the mediator between God and humanity), but also on a history of eroticized encounters between worshippers and Christ's body. This is the body of the Five Wounds, an elaborated trope in which each of the crucifixion wounds (hands, feet, side) is worshipped in turn - and each wound is a site of instability, where humanity and divinity coincide. Christ suffers these wounds to his human body so that he can, in his divine being as Son of God, secure the salvation of humanity. At each site the worshipper contemplates the wound in an act of imitation, the Imitatio worship of early Christianity, through which the worshipper attempts to feel with Christ's pain - to engage not only spiritually or intellectually but also physically (which 
sometimes led to literal imitations of the crucifixion wounds). This created its own erotics, a feeling-with the pain of the human Christ that linked the worshipper somatically to the worship. And the wounds, as sites where the body boundary is breached, also invite the worshipper into the body of Christ, haptically creating the sensation of penetration/being penetrated that is fundamental to sexual unionii. This complex erotics has always attended Christian worship in various forms and gives it extraordinary power not only spiritually, but also corporeally (physically, emotionally, intellectually), in the formation of individual Christian subjects.

By participating in the erotics of the hybrid (human-divine) figure of Christ, the hybrid (human-machine) figure of the cyborg accrues both that figure's corporeal appeal and its power, the transcendent power of the divine. So this prosthetic image of the cyborg mobilizes both the erotics of power associated with the 'extension' metaphor, discussed earlier, and the sexual erotics associated with the hybrid image through its cultural association with the image of Christ.

The figure was particularly popular through the 1980s and 1990s, with fictional representations ranging from the androids of Bladerunner (1982), James Cameron's Terminator characters $(1984,1990)$, DATA, the Borg and Seven-of-Nine in Star Trek: The Next Generation (1988-1994) and Star Trek: Voyager (1995-2001), and the Cybermen episodes of Doctor Who (2006). In everyday life it accustomed us to the sight of rational human beings walking the streets apparently talking to imaginary companions, but actually communicating via ear-pieces attached to mobile phones. Though perhaps a closer analogue is the blue-tooth device that declares its prosthetic nature to the world, and includes its wearer in the privileged group of the technologically-extended or enhanced. This device prompted several episodes of Doctor Who featuring cyborg characters, the Cybermen. Writer and producer, Russell T. Davies and main actor, David Tennant (The Doctor) explained in a post-episode documentary that the Cybermen episodes, most 
notably 'Rise of the Cybermen' and 'Age of Steel' (2006), engage directly with the fears and desires provoked by this technology:

Davies: 'People want to relate to technology, that's... what they're after. And, you know, how many people do you see walking around with the bluetooth attachment now... Tapping into modern paranoias and modern obsessions, things that people get joyous about as well - upgrading, that notion of upgrading, that notion that every year you can change your phone, you can change your FE3 player, and if you don't keep up with the technology, then you're going to be left behind.'

Tennant: 'I think it's always good to just tap into those slight worries that people have about modern life - mobile phones which people are now absolutely reliant on and yet at the same time I think we're all slightly nervous about. We don't really understand them, most of us. We don't really know how this information comes into this little plastic thing that we carry about...That's where all the cybermen come from anyway, this whole idea that the modern technology will slowly replace us, and that modern technology is out to get us...That's what we see throughout that episode, just this whole idea that it will slowly creep up on us and we won't quite notice it happening, which just makes it that worrying bit closer.'

This complex of fear and desire reflects our ambivalence about using technology that is so close to us physically; we don't have the same fear about our cars or the planes we use to travel around the country, or refrigerators with various ICT functions. However, when these devices begin to enter the gestalt of our physical being, to connect with us in ways that challenge bodily boundaries and the autonomy of the individual (a major concern of the Doctor Who episodes, as of the Star Trek stories of collective entities such as The 
Borg), then they both become a challenge and require an effort of the imaginary to accommodate.

\section{AUGMENTATION}

One of the most recent imaginary versions of this figure - complete with Christian references - is in the Wachowski brothers' films of the Matrix $(1999,2003,2003)$. The Neo character (played by Keeanu Reeves) represents another take on this process of technological hybridization - not so much enhancement but augmentation. Neo moves through the Virtual Reality spaces of the Matrix as a result of his blending with the machine. Like the earlier Neuromancer fantasies on which the films are based, the VR travelers of the Matrix films physically interface with the technology via neural jacks in their necks. And when traveling in the Matrix, they leave their physical bodies behind and vulnerable, though their minds are free to wander in a digital body freed of many of the physical constraints of everyday life; hence the extraordinary, gravity-defying acrobatics of Neo and his companions (Cranny-Francis, 2005). The Matrix films mobilize the earlier, extension metaphor that we associate with VR applications as well as the later enhancement metaphor where the relationship between human and machine is hybrid. It is not, therefore, surprising to find the Neo character explicitly positioned in a Christ-like role, as the saviour of humanity.

Augmentation, as explained by Ana Viseu, is another way of thinking about the nature of this relationship. Viseu documents what she sees as the move from simulation, which uses 'replication and separation' (typical of VR) as guiding principles, to augmentation, which uses 'connectivity and responsiveness' (Viseu, 2003: 17). She also refers to William Mitchell's study, City of Bits (1999), which maps this move in the technological imaginary:

Initially, the physical was pushed into the digital, giving rise to digital artifacts that looked like their physical counterparts (e.g. desktop icons). 
Now, we are moving towards a phase of "functionality without virtuality" ... where the digital is pushed into the physical, creating artifacts whose digitality is hidden. A number of artifacts are exemplars of this: wearable computers, conductive fabrics that work as touch screens (Kahney 2000), newspaper headline scanners that connect directly to the internet (Guernsey 2000), air conditioners with communication capabilities (O'Connell 2001), and artifacts that track patients' weight loss (Knapp 2000). (Viseu, 2003: 17-18)

And Viseu notes that a major difference here is that in the second phase the digital component is meant to be pervasive but not necessarily visible. In the earlier, extension phase the visibility of the technology was a crucial part of its appeal; its erotics. The consequence of the invisibility of the technology in the augmentation phase is, for Viseu, the production of the hybrid (the cyborg).

It is worth considering this point further since the hybrid for Viseu includes constructs such as the U.S. military's Land Warrior program, the aim of which is to produce a technologically augmented soldier. And Viseu includes quotes from the Land Warrior web site in her description:

Armed with this technology the soldier becomes "a totally, 100 percent integrated system. ... Th[e] computer ... basically control[s] and manage[s] all the subsystems he's wearing" ... his body is transformed into a personal-area network, and becomes a node within the larger network. (p. 19)

As noted in the discussion of the cyborg above, hybridity is not necessarily socially and culturally critical and the Land Warrior soldier clearly is not. Furthermore, to many 
contemporary readers it is unlikely that his technology is invisible; it is more likely to seem a more comprehensive example of extension. The FutureWarrior image that can be found on the U.S. Army's web site is, in fact, striking for its similarity to the fictional character, Robocop in Paul Verhoeven's film of that name (1987).

In these examples of hybridity it may be that the individual technological applications are not so visible (e.g. the electronic fibres or nanotube laminates in the soldier's uniform); however, the augmented nature of the "personal-area network" is quite apparent. Viseu notes that this represents a fundamental change in attitudes to embodied human being: 'Here, the human is no longer the measure of all things, the entity that machines are designed to imitate. The human body is viewed as being deficient, in need of improvement, of being enhanced with computing capabilities.' (p. 18). This is no longer the mind-in-a-vat of the VR imaginary but a construct in which the human body is augmented technologically, under the control of the rational human mind. Or is it?

The ambivalence in our attitudes to the cyborg and to hybridity seems to resolve on this question of how this new entity is characterized and what constitutes its intelligence, for as Viseu goes on to note, 'the augmentation of the physical through the digital does not result in physical plus digital, but in a new entity with its own specificities' (p. 22). The ontological status of Locutus of Borg analysed above was seen to resolve on the control established over the cyborg complex by the human mind of Picard. The nightmare scenarios in most science fiction narratives of hybridity occur when the technology colonizes the human mind, turning it into something 'other'. These scenarios usually present an artificial intelligence vanquishing the human elements of the hybrid, conventionally presented as 'the emotions'. When the human is gone, there are no emotions; there are also no verbal contractions in the entity's diction! 
The other possibility is that suggested by Viseu, of a synergy between human and technology - a new entity with a different kind of being, including a different kind of intelligence, a different sensorium, a different way of being-in-the-world (to use Heidegger's sense of that term). This may be problematic and Viseu refers to the example of a work wearable that 'can be programmed to, after five minutes of perceived inactivity inactivity being defined the wearable's owner, not its user - send a message directly to the wearer's retina saying 'go back to work'.' (p. 23). Elsewhere I have considered in some detail the way in which the FutureWarrior type hybrid can be seen in Heideggerian terms as creating a 'standing reserve' that has no regard for the individual subjects (human and/or hybrid) that comprise it (Cranny-Francis, 2007, 2008). As 'a node within the larger network' the hybrid entity may be subject to decision-making processes that disregard or diminish the importance of her/his/its individual being (though this may not be at odds with the ethics of the new hybrid entity, which may be more collective).

Alternatively, we might posit a very different kind of outcome of this hybridity, with reference to Medard Hilhorst's discussion of 'prosthetic fit' (Hilhorst, 2004).

\section{PROSTHETIC II: DIFFERENCE}

Hilhorst's article considers a highly-coloured hook prosthesis designed for children who are missing a hand, and compares responses to it with responses to the more conventional prostheses - the flesh-coloured artificial hand that most parents favour for their children and the more utilitarian hook. Hilhorst's interest is in the social implications of the children's choice of the colourful prosthetic that is patently artificial. He notes that:

One can call it a 'prosthesis' (substitute) or 'orthosis' (extension), as long as one does not suggest the connotations that often go with that to make a body more complete, to fill up what is missing, to repair a deficient 
body, to restore normality, etc. Its colors alone suggest a different message ... (Hilhorst, 2004: 304)

Hilhorst identifies that message as: "'this object can be displayed,and the person who wears it (you, I) may also certainly display herself in this way'” and adds: 'A message like this comprises both an invitation and an encouragement: the individual is invited to wear the prosthesis with self-awareness, but it also supported by the message to do so with self-confidence.' (p. 305) This offers a useful counter to dystopian visions of prosthetic technologies, arguing instead that: 'the person who chooses to wear this device emphasizes the value to herself - as she sees it - of her bodily difference, and perhaps also the importance of it for those meeting her.' (p. 305) In other words, whether we focus specifically on the human actor or on the human-prosthetic hybrid, what this choice represents is an acceptance, even declaration, of difference and of specificity.

If we refer this argument to Viseu's discussion of the hybrid, we find a real-world example of that new synergy to which she refers - a hybrid with her own specificity, able to act out of that specificity. Which does not discount the other possibility, of a prosthetic that colonizes the embodied subject, converting her/him into a 'nodal point'. It simply makes the point that this is not the only or inevitable outcome. The hybrid may be the prostheticwearer who chooses to proclaim her difference from others by using a patently artificial prosthetic and who is effectively supported in that declaration by its usefulness and appeal. Hilhorst's argument is that this is also a powerful support to the individual subjectivity of that wearer.

We might refer this argument also to contemporary applications such as CuteCircuit's HugShirt (Cranny-Francis 2007, 2008). The HugShirt uses electronics to create the sensation of a hug in the wearer of a sweatshirt: 
The system is very simple: a Hug Shirt (Bluetooth with sensors and actuators), a Bluetooth java enabled mobile phone with the Hug Me java software running (it understands what the sensors are communicating), and on the other side another phone and another shirt. If you do not have a Hug Shirt but know that your friend has one you can still send them a hug creating it with the HugMe software and it will be delivered to your friend's Hug Shirt!

When touching the red areas on your Hug Shirt your mobile phone receives the sensors data via Bluetooth (hug pressure, skin temperature, heartbeat rate, time you are hugging for, etc) and then delivers it to the other person. (CuteCircuit, on-line)

Is the wearer of the HugShirt complicit in the replacement of actual human intimacy by human-machine interaction? This is one question that is commonly prompted by the HugShirt and by other wearables that are used in applications that enable a remote form of sensory interaction: do they represent the destruction of the human sensorium and its replacement by the cold heart of technology?

With reference to the work of Hilhorst we might argue instead that the HugShirt-wearer is an example of the hybrid who declares her/his/its difference and specificity. That this is not about the destruction of the human senses but about another sensory experience altogether. As Francesca Rosella of CuteCircuit has explained, the sender of the Hug and the wearer of the HugShirt are engaged in a new choreography of space-time. The sender has taken the time to choose the hug (from a set of choices), and the wearer of the HugShirt has accepted it; together they create a unique experience, which is the sensory pleasure of the receiver and the affective delight and, we might suggest, proprioceptive sensation of the hug experienced by the sender. The experience of both is based, in this 
scenario, on the bodily memory of past hugs (Rosella, personal communication 2006). Neither the sender nor the wearer is pretending that this is a human hug; rather both accept the experience as of another order but one that has its own modality and own value.

Sharon Baurley of the University of the Arts in London has also worked extensively on clothing that reacts to mobile phone signals: for example, narrow pleating in a sleeve that contracts and expands to convey the sensation of a caress, warming pads that heat up to convey the warmth and pressure of bodily contact. One of the participants in Baurley's experiments confirmed Francesca Rosella's views on the value of this communication when he said:

Just the fact that you are linked, you are communicating and you are linked through several senses. If you are facing someone you have visual, tactile, spoken word, etc. And when you are remote you can't see that person all you have is text, spoken word, but if you can see things are happening to this person at the other end, you feel closer to that person. (Baurley, 2006)

Again there is no pretence that this is the equivalent of a human touch; rather it is another way of touching, of creating communication and intimacy. It is that different experience, that different knowledge that constitutes the hybrid of Viseu's discussion.

\section{ENGAGEMENT}

The technological sophistication shown by the users of a range of contemporary applications such as Baurley's wearables (quoted above), introduces the final metaphor I want to address in this paper - which is engagement. Engagement evokes an imaginary that acknowledges the artificiality of technology, but neither rejects nor colonizes it. 
Instead it interfaces with the technology in a sensuous way, exploring its difference, combining with it to create a new coupling - which is the hybrid.

In their paper, "Wearable Music in Engaging Technologies" (2007) Franziska Schroeder and Pedro Rebelo propose the relationship between the musician and her instrument as a model for human-machine interaction:

We address the relationship between a music performer and her instrument as a possible model for re-thinking wearable technologies. Both musical instruments and textiles invite participation, and by engaging with them we intuitively develop a sense of their malleability, resistance and fragility. In the action of touching we not only sense, but more importantly, we react: we adjust the nature of our touch according to a particular material's property. (Schroeder and Rebelo, 2007: 85)

Schroeder and Rebelo note that the metaphor of extension has been applied to the relationship between performer and instrument, so that the instrument is seen as way of 'voicing one's body' (p. 87). In their view this conception of the relationship is inadequate because it elides the role of the instrument itself in creating music. They propose instead a relationship of 'participation and engagement, in which the instrument itself suggests to us specific ideas of its texture and materiality. This means that the performer only becomes acquainted with the "thing" at hand by being able to test boundaries, negotiate subtleties and uncover threshold conditions.' (p. 88) They give the example of performer, David Moss who describes his relationship with his drums in these terms: 'when I touch the rough, textured surface of a drum-skin (which was once a cow's skin!) I feel the story of time in the tiny (im)perfections, edges, ridges, and anti-gravity veins of former life' (Moss quoted in Schroeder and Rebelo, p. 88). This they characterise as a relationship of specificity, rather than adaptability; the technology (here, the musical instrument) is not 
made invisible or imperceptible, but rather embraced in its difference and specificity - like the colourful prosthesis discussed earlier.

This approach suggests that, rather than regarding the instrument as a seamless merging with, or a seamless extension of the body, the discontinuity between the performer and the instrument becomes the main concern.

In this line of thinking, the idea of seamlessly merging objects, which is often promoted in wearable technologies, neglects this intricate and vital relationship of performer/instrument. (p. 88)

And they go on to note that the strategy of invisibility often applied to the design of wearable technology would, if applied to music, have 'robbed us of Jimi Hendrix's guitar feedback, John Coltrane's unique saxophone sound and John Cage's prepared piano' (p. 90). It was the sensuous engagement of Hendrix with his guitar - his tortured love for the instrument expressed in his manipulation of it - that created his unique sound; not the elision of the guitar. Similarly, it is Coltrane's part-teasing, part-mastering courting of the saxophone that creates his music, and Cage's idiosyncratic deconstruction of the normative piano that produces his distinctive sound.

If we extend this to wearable technologies, as Schroeder and Rebelo argue, we have a model for engagement that is not relegated to the realms of virtuality, or of rationality, but that is felt deep in the body. It is an engagement that demands sensuous response to the material technology that is encountered (akin for Schroeder and Rebelo to 'itching and scratching' (p. 87)), so that this response is part of (and recognized as part of) the process of using the technology, which constitutes the (human-technology) hybrid. The argument for this sensuous engagement is not simply that it makes the human subject more selfconscious and self-reflexive in using technology, but also that it brings our attention back 
to the materials we are using in a creative way. As Schroeder and Rebelo argue: 'Let us think what type of musical instrument a silk scarf might become, before incorporating a keyboard into it.' (p. 90) In other words, before imposing some preconceived notion (derived from a different technology) of what a particular application might be, first explore the properties of the materials with which we are working and look at how the materials themselves might enable the desired result.

\section{Material culture/bodily engagement}

Jewellers have had a particular role in this re-discovery of contemporary material culture. As Wallace, Deardon and Fisher note: 'The fact that jewellery relates to the body or is worn close to the body, within the wearer's personal space, gives it a particular intimacy that may be absent from other objects or devices that we encounter.' (Wallace, Deardon and Fisher, 2007: 54-55) Contemporary jewellery, for them, is not about the fashion of the high-street but about the re-definition of our relationships with objects, the environment and each other: ' $\ldots$ contemporary jewellery develops a discourse about relationships: between self and object, individuals and groups, maker, audience and practice.' (p. 56) And they are writing this in the context of exploring the meanings and possibilities of digital jewellery, also the focus of research and practice for Edinburgh jeweller and researcher, Sarah Kettley.

In an article that describes her experiments with speckled computing in jewellery and its use by female friendship groups Kettley concludes: 'Contemporary craft practice was found to be embodied, or 'smeared', in a continuous and apparently inefficient way across the previously discrete steps of the design process.' (Kettley 2007b: 13) As a result there is no discrete separation of object or artefact from user, of design from material, or of designer from wearer; instead Kettley proposes a model of craft practice that engages all interactants as well as the material, social and cultural practices in which they are engaged. Kettley concludes: 
It seems that contemporary craft is well placed to inform the critical design of ubiquitous wearable artifacts with social meaning, and that an alternative market area may be available to the paradigm should a real commitment to thoughtful practice be made. As a result, it is recommended that crafts practitioners seek to position themselves, as designers and artists are doing, as informed and available to such practice, and that wearables developers actively consider contemporary craft as a resource in approaching social complexity in design. (p. 13)

This move to a craft paradigm, with its focus on embodiment and materiality, indicates dissatisfaction with the distanced, removed, rationalist assumptions of computing science - and with a notion of design that is separate from the development of the artifact (brought in to the process at the end to make the product attractive to users). Implicit in all of these

descriptions - and explicit in that of Schroeder and Rebelo - is an erotics not of power and control, but of touching and being touched - of an intense being-with that transforms the technology from an artifact to an experience - which subsequently becomes an aspect of the negotiated being of the user.

\section{FROTTAGE}

Philosopher, Andy Clark writes of successful interfaces: 'What makes such interfaces appropriate as mechanisms for human enhancement is, it seems, precisely their potential role in creating whole new agent-world circuits.' (Clark, 2007: 265) Again, we might think of those 'agent-world circuits' as hybrids or cyborgs, with Clark's formulation - like the explanations by jewellers (above) of the engagement with material culture - revealing the active, process-driven nature of that entity. 
In the same paper Clark theorizes how embodied subjects interact with technology, as they always have, to create new ways of doing and being, new knowledges. Human brains operate, he argues, not as some kind of library with a fixed body of information to which all experience is referred, but as

... promiscuously body-and-world exploiting. They are forever testing and exploring the possibilities for incorporating new resources and structures deep into their problem-solving regimes ... the minds of ... systems continuously re-negotiating their own limits, components, datastores and interfaces. (p. 277)

The consequence of this understanding of embodied being is that the body (any given biological or bio-technological body) is both critically important and constantly negotiable.' (p. 277) This is to say, the body interacts interrogatively and creatively with the material culture of technology to create new knowledge, which simultaneously re-negotiates the nature of that embodiment. Clark goes on to note that the nightmare visions of human minds taken over by technology (e.g. artificial intelligence) relies on a static, nonnegotiative model of human agency:

But human minds are not old-fashioned CPU's trapped in fixed and increasingly feeble corporeal shells. Instead, they are the surprisingly plastic minds of profoundly embodied agents: agents whose boundaries and components are forever negotiable, and for whom body, thinking, and sensing are woven flexibly (and repeatedly) from the whole cloth of situated, intentional action. (p. 278)

Clark's argument again provides a gloss to the research described by the jewellers in the previous section, specifying the role of bodily engagement with technology in the formation 
of human being. The value of Clark's formulation is that it locates this bodily engagement not as something new, but as a fundamental aspect of embodied human being, which is endlessly negotiable. So there is no need to fear the engagement with new technologies as it is, in Clark's theory, simply evidence of the problem-solving work of human being in action. We notice it simply because the technology is new, not yet naturalised as part of everyday life.

I called this final section 'frottage' in order to capture - though without its perverse meaning - the kind of rubbing against or rubbing together that constitutes this bodily engagement. One of the meanings of frottage is 'the obtaining of sexual pleasure by rubbing the clothed body against that of others' (Encarta Encyclopedia, on-line) though this meaning refers also to the perverse practice of rubbing up against strangers without their consent. It is frustrating that there is no commonly available term in English to describe the productive pleasure of rubbing against something - masturbation, probably the closest. Yet this too is a specifically sexual form of rubbing. The term we need to capture this re-visioning of the human-technology relationship is something like the AnloEwe term described by anthropologist, Kathryn Lynn Geurts - seselelame, which she translates as 'feel-feel-at flesh-inside' and which expresses the sensory interplay that forms the basis of consciousness in the culture of the Anlo-Ewe people of West Africa (Geurts, 2005: 175). As Clark and many of the theorists discussed in this essay have argued, contemporary western consciousness is similarly grounded in and dependent on a fully embodied engagement with the world, including the technologies that are characteristic of contemporary western societies. This is a sensory engagement which is sexual but also sensual and sensuous, and which exists not in isolation from mind or intellect but as part of the 'agent-world circuit' that is our being-in-the-world.

We engage with these new technologies and applications through our senses, our emotions, and our intellect - that is, fully corporeally - and it is this complex engagement 
that enables us to embed these technologies in our lives. It is also what enables us, at times, to create ways of using applications unforseen by their designers: the popularity of text-messaging being a major contemporary example. As many of the theorists/creators (jewellers, designers, musicians) discussed above argue, the most appropriate metaphor for this interaction is one that acknowledges the intense sensory nature/pleasure of that engagement, for which they use a range of tactile metaphors. The important distinction they draw is between a hybrid or cyborg figure in which the technology has been elided or subsumed by the human (or, in nightmare scenarios, has taken over the human) and one in which the human-technology interaction is perceptible, self-conscious, negotiative, knowing - a source of pleasure, creativity, and of increased self-knowledge, as well as of new knowledge.

In our engagement with wearable technology we have a range of possible imaginaries available to us, including human-tool extension, prosthetic enhancement, humantechnology augmentation, and bodily engagement. In each case the figure of the humanmachine hybrid or cyborg is a shadowy presence, which sometimes offers the possibility of a being beyond the known and familiar, sometimes simply reiterates and reinforces the known. Wearable technology can be conceived and analysed by reference to all of these imaginaries, and each yields its own possibilities and concerns. However, it is the most recent work arguing for specificity of engagement with the material culture of the technology that seems most productive now. And it is no accident that this comes at a time when western societies are reconsidering the role of the senses in our engagement with the world - and hence the role of the senses in the formation of individual subjectivity and in the generation of knowledge. It is precisely the demand on/for bodily engagement made by new technology that has necessitated this re-negotiation. And it is that renegotiation that can lead to the most creative ways of using the potentials opened up by technology in a range of fields, including that of wearable technology. 


\section{REFERENCES}

'Frottage', in Encarta Encyclopedia, URL consulted 26/3/2008:

http://uk.encarta.msn.com/encnet/refpages/search.aspx?q=frottage

Adams, D. (2005) 'Smart Cloth for Cutting-Edge Tailors', Solve: A CSIRO

Review of scientific innovations for Australian industry, Issue 2, URL (consulted December, 2006): http://www.solve.csiro.au/0205/article9.htm

Ash, J. (1990) 'The Discursive Construction of Christ's Body in the Later Middle Ages: Resistance and Autonomy', in T. Threadgold and A. Cranny-Francis (eds) Feminine/Masculine and Representation. Sydney: Allen \& Unwin

Baurley, S. (2006) 'The user as focus and inspiration for smart innovation', paper presented at "How Smart Are We?" Symposium, RIBA, London, 15 September.

Beckwith, S. (1993) Christ's Body. Identity, Culture and Society in Late Medieval Writings. London: Routledge

Berzina, Z. (2004) Skin Stories: Charting and Mapping the Skin, Ph.D. thesis, London College of Fashion, London University of the Arts.

Bynum, C. W. (1995) The Resurrection of the Body in Western Christianity, 2001336. N.Y.: Columbia University Press.

Bynum, C. W. (1991) Fragmentation and Resurrection: Essays on Gender and the Human Body in Medieval Religion. N.Y.: Zone Books.

Charlesworth, J. (2007) 'Wearables as "relationship tools", Al and Society, Vol.22 (No.1): 63-84.

Chesher, C. (1997) 'The Ontology of Digital Domains', in D. Holmes (ed) Virtual Politics: Identity and Comnmunity in Cyberspace, pp. 79-92. London: Sage.

Clark, A. 'Re-Inventing Ourselves: The plasticity of embodiment, sensing, and mind', Journal of Medicine and Philosophy, Vol. 32: 263-282.

Cranny-Francis, A. (1995) The Body in the Text. Melbourne: Melbourne University Press. 
Cranny-Francis, A. (2000). 'The erotics of the (cy)Borg: authority and gender in the sociocultural imaginary', in M. Barr (ed) Future Females, the Next Generation: New Voices and Velocities in Feminist Science Fiction, pp. 145-163. Totowa, N.J.: Rowman and Allenheld.

Cranny-Francis, A. (2005) 'Moving the Matrix: kinesics, space and embodiment in the Matrix trilogy', in S. Gillis (ed), The Matrix: Cyberpunk Reloaded, pp. 101113. London: Wallflower Press.

Cranny-Francis, A. (2006) 'Somatic Technologies: Embodiment, New Technologies and the Undead', Scan: Journal of media arts culture, Vol.3 (No.3), URL (consulted xxxx): http://scan.net.au/scan/journal/display.php?journal id=84

Cranny-Francis, A. (2007) 'Ecce techno, or, Suiting the biomechanical platform: immersion and contemporary embodiment", Visual Communication, Vol.6 (No.2): 156-169.

Cranny-Francis, A. (2008) 'Fabric(ated) Ontologies: the biopolitics of smart design in clothing and jewellery', paper presented at

CuteCircuit, URL (consulted January 2008):

http://www.cutecircuit.com/now/projects/wearables/fr-hugs/

Fuchs, C. J. (1995) "'Death is Irrelevant": Cyborgs, Reproduction, and the Future of Male Hysteria' in C.H. Gray (ed) The Cyborg Handbook, pp. 281-300. N.Y.: Routledge.

Geurts, K.L. (2005) 'Consciousness as "Feeling in the Body": A West African Theory of Embodiment, Emotion and the Making of Mind', in D. Howes (ed.) Empire of the Senses: The Sensual Culture Reader, pp. 164-178. Oxford \& NY: Berg.

Gibson, W. (1986) Neuromancer. London, Grafton.

Grosz, E. (1989) Sexual Subversions: Three French Feminists. Sydney: Allen \& Unwin.

Haraway, D. (1991) Simians, Cyborgs, and Women: The reinvention of nature. N.Y.: Routledge 
Haraway, D. (1991) 'A Cyborg Manifesto: Science, Technology, and Socialist-

Feminism in the Late Twentieth Century', in Simians, Cyborgs and Women:

The Reinvention of Nature, pp. 149-181. New York: Routledge.

Haraway, D. (1997)

Modest_Witness@Second_Millenium.FemaleMan@_Meets_OncoMouse ${ }^{\mathrm{TM}}$.

N.Y. \& London: Routledge

Hayles, N. K. (1999) How We Became Posthuman: Virtual Bodies in Cybernetics, Literature, and Informatics. Chicago: University of Chicago Press.

Hayles, N. Katherine. (2002) 'Flesh and Metal: Reconfiguring the Mindbody in Virtual Environments', Configurations, Vol.10: 297-320.

Heidegger, M. (1993) 'The Question Concerning Technology' in D.F. Krell (ed) Basic Writings. From Being and Time (1927) to The Task of Thinking (1964), pp. 311-341. London \& New York: Routledge.

Heiss, L. (2007) 'Enabled apparel: The role of digitally enhanced apparel in promoting empathic connection', Al and Society, Vol.22 (No.1): 15-24.

Hilhurst, M. (2005) 'Prosthetic fit': On personal identity and the value of bodily difference', Medicine, Health Care and Philosophy, Vol.7 (No.3): 303-310.

Howes, D. (2005) Empire of the Senses: The Sensual Culture Reader. Oxford: Berg.

Jewell, L. (2006) 'Year 2025: Army's Futuristic Uniform', Military.com, URL (consulted March, 2008):

http://www.military.com/soldiertech/0,14632,Soldiertech_FutureUni,,00.html

Kettley, S (2007a) 'Distribution - craft and speckled computing', URL (consulted July 2007): http://www.craftaustralia.com.au/research/20070327.php

Kettley, S. (2007b) 'Crafts praxis for critical wearables design', Al and Society, Vol.22 (No.1): 5-14.

Latour, B. 2003, 'Do You Believe in Reality? News from the Trenches of the Science Wars?' in R C Scharff \& V Dusek (eds), Philosophy of Technology: The Technological Condition. An Anthology, pp. 126-137. Oxford: Blackwell. 
Pepperell, R. (2007) 'Applications for conscious systems', Al and Society, Vol.22 (No.1): 45-52.

Rebelo, P. (2006) Haptic Sensation and Instrumental Transgression', Contemporary Music Review, Vol. 25 (No.1-2): 27-35.

Rhodes, B. 'A brief history of wearable computing', URL (consulted March, 2008): http://www.media.mit.edu/wearables/lizzy/timeline.html

Rosella, F. (2006) Personal communication.

Schroeder, F. and Rebelo, P. (2007) 'Wearable music in engaging technologies', Al and Society, Vol.22 (No.1): 85-91.

Steinberg, L. (1996) The Sexuality of Christ in Renaissance Art and in Modern Oblivion. Second edition, revised and expanded. Chicago \& London: University of Chicago Press.

Steinmair-Pösel, P. 'Imitatio Christi and the Concept of Grace', URL (consulted November, 2006):

http://www.cla.purdue.edu/academic/engl/conferences/covar/Program/posel.p $\underline{\mathrm{df}}$

Thompson, S. (2007) “Mind the gap: technology as soma', Al and Society, Vol.22 (No.1): $37-44$.

Valigra, L. (2002) 'Fabricating the Future', The Christian Science Monitor, August 29, URL (consulted March, 2008):

http://www.csmonitor.com/2002/0829/p11s01-stgn.html

Viseu, A. (2003) 'Simulation and augmentation: Issues of wearable computers', Ethics and Information Technology, Vol.5 (No.1): 17-26.

Wallace, J., Dearden, A. and Fisher, T. (2007) 'The significant other: the value of jewellery in the conception, design and experience of body focussed digital devices', $A$ l and Society, Vol.22 (No.1): 53-62.

Warwick, K. (2003) 'Cyborg morals, cyborg values, cyborg ethics', Ethics and Information Technology, Vol.5 (No.3): 131-137. 


\section{FILM AND TELEVISION}

'Rise of the Cybermen' and 'The Age of Steel' Doctor Who. (2006) BBC Cardiff.

'The Best of Both Worlds, Part l' and 'The Best of Both Worlds, Part Il'. Star Trek: the Next Generation. (1990) Paramount Pictures Corporation.

Cameron, J. (dir.) (1984) The Terminator. Orion/Hemdale/ Pacific Western

Cameron, J. (dir.) (1990) Terminator 2: Judgment Day. Pacific Western

Kubrick, S. (dir.) (1968) 2001: A Space Odyssey. Metro-Goldwyn-Mayer.

Scott, Ridley (dir.) (1982) Blade Runner. Warner/Ladd/Blade Runner Partnership

Star Trek: the Next Generation. (1988-94) Paramount Television.

Star Trek: Voyager. (1995-2001) Paramount Television.

Verhoeven, Paul (dir.) (1987) Robocop. Rank/Orion

Wachoski, Larry and Andy. (dirs) (1999) The Matrix. Village Roadshow/Silver.

Wachoski, Larry and Andy. (dirs) (2003) The Matrix Reloaded. Warner Brothers.

Wachoski, Larry and Andy. (dirs) (2003) The Matrix Revolutions. Warner Brothers.

\footnotetext{
i My thanks to Cathy Hawkins for this point

ii My argument here is that the worshipper deploys the haptic sense of proprioception - the internal sense of being in space/time - to generate a feeling-with the sufferings of Christ
} 